\title{
The Sinorhizobium meliloti EmrR Regulator Is Required for Efficient Colonization of Medicago sativa Root Nodules
}

\author{
Mário R. Santos, ${ }^{1}$ Andreia T. Marques, ${ }^{1}$ Jörg D. Becker, ${ }^{2}$ and Leonilde M. Moreira ${ }^{1,3}$ \\ ${ }^{1}$ IBB-Institute for Biotechnology and Bioengineering, Centre for Biological and Chemical Engineering, Instituto Superior \\ Técnico (IST), Lisbon, Portugal; ${ }^{2}$ Instituto Gulbenkian de Ciência, Rua da Quinta Grande No. 6, 2780-156 Oeiras, Portugal; \\ ${ }^{3}$ Department of Bioengineering, IST, University of Lisbon, Av. Rovisco Pais, 1049-001 Lisbon, Portugal
}

Submitted 25 September 2013. Accepted 19 December 2013.

\begin{abstract}
The nitrogen-fixing bacterium Sinorhizobium meliloti must adapt to diverse conditions encountered during its symbiosis with leguminous plants. We characterized a new symbiotically relevant gene, emrR (SMc03169), whose product belongs to the TetR family of repressors and is divergently transcribed from $e m r A B$ genes encoding a putative major facilitator superfamily-type efflux pump. An emrR deletion mutant produced more succinoglycan, displayed increased cell-wall permeability, and exhibited higher tolerance to heat shock. It also showed lower tolerance to acidic conditions, a reduced production of siderophores, and lower motility and biofilm formation. The simultaneous deletion of $e m r A$ and $e m r R$ genes restored the mentioned traits to the wild-type phenotype, except for survival under heat shock, which was lower than that displayed by the wild-type strain. Furthermore, the $\Delta e m r R$ mutant as well as the double $\triangle e m r A R$ mutant was impaired in symbiosis with Medicago sativa; it formed fewer nodules and competed poorly with the wild-type strain for nodule colonization. Expression profiling of the $\Delta e m r R$ mutant showed decreased expression of genes involved in Nod-factor and rhizobactin biosynthesis and in stress responses. Expression of genes directing the biosynthesis of succinoglycan and other polysaccharides were increased. EmrR may therefore be involved in a regulatory network targeting membrane and cell wall modifications in preparation for colonization of root hairs during symbiosis.
\end{abstract}

Sinorhizobium meliloti 1021 interacts with legume roots inducing the formation of nodules, within which this bacterium fixes nitrogen to ammonia that becomes available to the plant. The $S$. meliloti TolC protein is required to establish a successful nitrogen-fixing symbiosis with Medicago plants and is necessary for protein and exopolysaccharide secretion and protection against osmotic and oxidative stresses. TolC interacts with membrane transporters to control cellular import and export of various compounds (Cosme et al. 2008). Comparison

Microarray data were deposited in the Gene Expression Omnibus (GEO) repository at National Center for Biotechnology Information under accession number GSE44607.

Corresponding author: L. M. Moreira; Telephone: (+351)218419031; Fax: (+351)218419199; E-mail: 1moreira@ ist.utl.pt

*The $\boldsymbol{e}$-Xtra logo stands for "electronic extra" and indicates that two supplementary tables are published online and Figure 6 appears in color online.

(C) 2014 The American Phytopathological Society of the transcriptomes of $S$. meliloti 1021 and the tolC mutant confirmed that the absence of functional TolC protein compromises cell homeostasis as reflected by the simultaneous increase in expression of many genes involved in cytoplasmic and extracytoplasmic stress responses (Santos et al. 2010). In the same transcriptomic study, SMc03167, SMc03168, and SMc03169 genes were found to be significantly upregulated in the $t o l C$ mutant. The two first encode a putative major facilitator superfamily (MFS)-multidrug resistance (MDR) efflux pump, and gene $S M c 03169$ encodes a putative transcriptional repressor of the TetR family. Other expression profiling analyses also showed that genes SMc03167, SMc03168, and SMc03169 were inducible by the presence of the flavonoid luteolin (Capela et al. 2005) under acidic $\mathrm{pH}$ (Hellweg et al. 2009) and under heat shock (Barnett et al. 2012), suggesting their involvement in response to stress.

Despite the importance of MDR efflux pumps in the active extrusion of toxic compounds from cells, their role is relatively unknown in plant symbiotic bacteria such as rhizobia. The flavonoid-inducible MFS-type multidrug efflux pump RmrAB from Rhizobium etli was shown to be required for nodulation of Phaseolus vulgaris and resistance toward phytoalexins, flavonoids, and salicylic acid (González-Pasayo and MartínezRomero 2000). In Bradyrhizobium japonicum, loss of the resistance-nodulation-cell division (RND)-type RagCD pump had no effect on the sensitivity to antimicrobial compounds or nodulation of soybean roots (Krummenacher and Narberhaus 2000), but another RND-type efflux pump, BdeAB, although not required for nodule formation, was essential for effective symbiotic nitrogen fixation in soybean nodules (Lindemann et al. 2010). In S. meliloti, a study involving the systematic deletion of genes encoding MFS-type and RND-type proteins resulted in the identification of the SmeAB RND-type pump as being important in nodulation competitiveness and in mediating resistance towards several antimicrobials, including plantderived compounds (Eda et al. 2011).

Deletion of the putative MFS-type transporter encoded by $S$. meliloti 1021 SMc03167 and SMc03168 genes did not affect either the sensitivity to several toxic compounds or the symbiotic properties of the bacteria (Capela et al. 2005; Eda et al. 2011). Nevertheless, the comparison of the transcriptome of $S$. meliloti 1021 in the presence or absence of the flavonoid luteolin, showed that the expression of genes SMc03167 and SMc03168 as well as the divergently transcribed gene SMc03169, encoding a putative regulator of the TetR family, was highly induced (Capela et al. 2005). Similar induction of gene expression by flavonoids was observed for other MFStype encoding genes relevant for the interaction of bacteria such as Erwinia amylovora (Burse et al. 2004) and Agrobacte- 
rium tumefaciens (Palumbo et al. 1998) with host cells. Recently, the expression of genes fre $C$, fre $A$, and fre $B$ encoding a putative RND-type efflux pump of $B$. japonicum was shown to be dependent on the flavonoid responsive transcriptional repressor FrrA of the TetR-family (Wenzel et al. 2012). Nevertheless, the deletion of frrA or fre $C$ genes had no effect on nodule number and plant appearance. As TetR-type regulators are encoded next to the genes encoding the efflux pump and some are flavonoid-responsive (Burse et al. 2004; GonzálezPasayo and Martínez-Romero 2000; Palumbo et al. 1998; Wenzel et al. 2012), we have investigated the role of the TetR regulator-encoding gene SMc03169 (emrR) of S. meliloti in symbiosis and other phenotypic traits including adaptation to stress conditions, exopolysaccharide and siderophore production, biofilm formation, and motility.

\section{RESULTS}

\section{Genomic location of SMc03167 to SMc03169 genes} from $S$. meliloti.

In $S$. meliloti 1021, genes with the locus tag SMc03167 and SMc03168 encode a putative efflux system of the MFS, with SMc03168 having the characteristics of a membrane fusion protein and SMc03167 the MFS-type transporter protein. Due to their similarity to the EmrA and EmrB efflux pump of Escherichia coli, this designation was kept (Fig. 1A), with SMc03168 and $S M c 03167$ being designated $e m r A$ and $e m r B$, respectively. Located about $300 \mathrm{bp}$ downstream of the $S M c 03168$ coding region and in opposite orientation is gene $S M c 03169$ (Fig. 1A). SMc03169 encodes a putative protein with 236 amino acids that shares an N-terminal sequence and structural similarities to members of the TetR family of transcriptional repressors. In conformity with the $E$. coli repressor controlling the expression of emrA and $e m r B$ genes (Lomovskaya et al. 1995), this gene was named $e m r R$. The search for conserved regions showed the DNA-binding helix-turn-helix motif in the N-terminal (Fig. 1B). The predicted ligand-binding domain is located within the C-terminal region, although, due to the diverse nature of this region, no conservation at the amino acid level was observed. As previous expression profiling showed that genes SMc03167, SMc03168, and SMc03169 were inducible by luteolin and under several stress conditions, our assumption was that these gene products might be important for $S$. meliloti adaptation to changing environments with possible influence on symbiosis.

\section{Phenotypes of $\triangle e m r B, \Delta e m r R$, and $\triangle e m r A R$ deletion mutant strains.}

$S$. meliloti 1021 deletion of emrB, emrR or emrAR genes was performed as described below. The deletion mutant of the emrB gene (Sm1021-7) showed similar growth behavior as wild-type Sm1021 in rich tryptone yeast (TY) and minimal glutamate-mannitol salts (GMS) media (data not shown). Antimicrobial susceptibility tests against an antibiotic (novobiocin), a dye (ethidium bromide), detergents (sodium dodecyl sulfate [SDS], deoxycholate [DOC]), oxidative stress agents $\left(\mathrm{H}_{2} \mathrm{O}_{2}\right.$, cumene hydroperoxide), and plant-derived compounds (berberine, $p$-coumaric acid, genistein) showed no difference in sensitivity between the $\Delta e m r B$ mutant and the wild-type Sm1021 (data not shown). Similarly, Medicago sativa seedlings inoculated with the wild-type Sm1021 and $\Delta e m r B$ mutant strains gave rise to a slightly lower nodule number in the presence of the deletion mutant, but plant dry weights were similar. Our results are in line with those obtained for the simultaneous deletion of SMc03167 and SMc03168 genes (Eda et al. 2011) or the SMc03167 gene only (Capela et al. 2005), which could not identify one or more substrates of this putative efflux pump or attribute a role in symbiosis.

The deletion mutant for the emrR gene (Sm1021-9) showed a specific growth rate similar to the one of the wild-type Sm1021 in complex TY medium (data not shown) and in minimal GMS (pH 7.0) medium (Fig. 2A). Nevertheless, when growing in this last medium, it showed higher growth deceleration after $24 \mathrm{~h}$ than the wild-type Sm1021, as indicated by optical density measurement (Fig. 2A). Determination of colony forming units (CFU) under those conditions confirmed the decreased growth of the $\Delta e m r R$ mutant when entering the stationary phase by comparison with the wild-type strain (data not shown). As previous expression profiling data in $S$. meliloti showed that gene emrR (SMc03169) was responsive to an acidic pH shift (Hellweg et al. 2009), we measured the external $\mathrm{pH}$ during growth in GMS medium. It was observed that, between 24 and $48 \mathrm{~h}$ of growth, the $\Delta e m r R$ mutant acidified

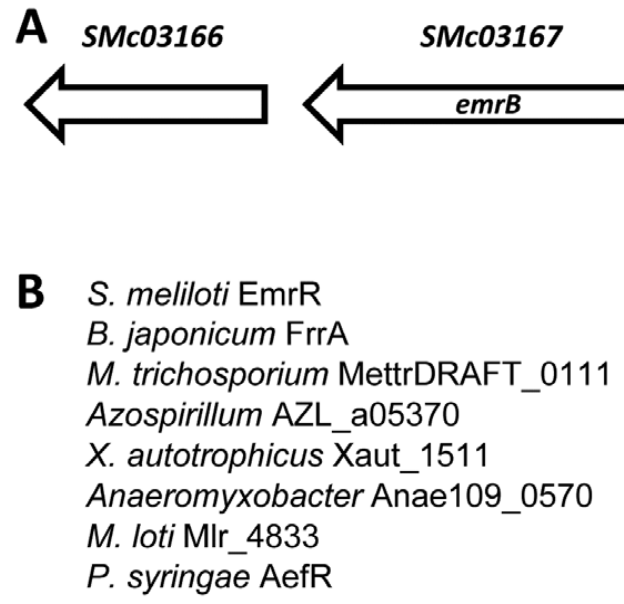

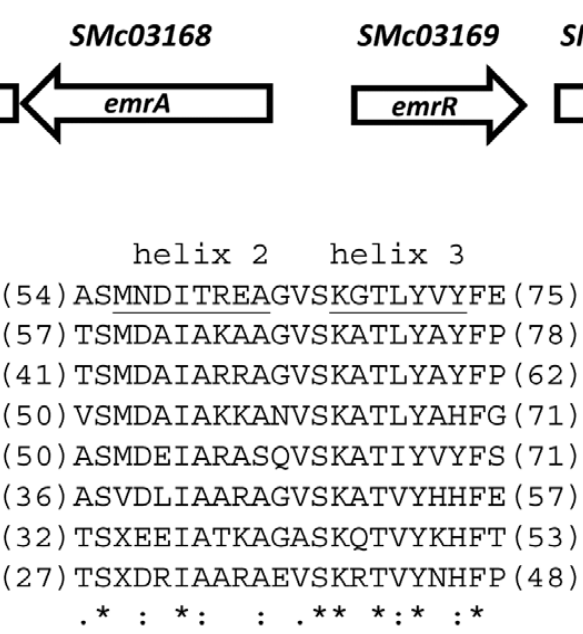

Fig. 1. A, Physical organization of Sinorhizobium meliloti 1021 SMc03167 (emrB) and SMc03168 (emrA) genes encoding a putative major facilitator superfamily-type transporter and SMc03169 gene (emrR) encoding a putative TetR transcriptional regulator. The flanking genes are SMc03170, encoding a putative transcriptional regulator of the AraC family, and $S M c 03166$, encoding a putative metallophosphoesterase. N = nucleotides. B, Partial multiple sequence alignment of helix-turn-helix (HTH) DNA-binding motif present in TetR-type regulators. The accession numbers of the proteins are $S$. meliloti 1021 (NP_387006.1), Bradyrhizobium japonicum USDA 110 (NP_770962.1), Methylosinus trichosporium OB3b (EFH05139.1), Azospirillum sp. strain B510 (YP_003450612), Xanthobacte autotrophicus Py2 (YP_001416416), Anaeromyxobacter sp. strain FW109-5 (YP_001377768), Mesorhizobium loti MAFF303099 (3BHQ), Pseudomonas syringae pv. tomato Dc3000 (3CDL). Asterisks indicate the amino acid residues that are identical in all the proteins; one or two dots indicate semiconserved or conserved substitutions, respectively. 
the medium by $1 \mathrm{pH}$ unit, while only a slight decrease was observed for the wild-type strain (Fig. 2A). To evaluate whether buffering the medium would prevent the acidification and the growth defect of the $\Delta e m r R$ mutant, strains were grown in morpholinepropanesulfonic acid (MOPS) buffered medium $(\mathrm{pH}$ 7.0). Results illustrated in Figure 2B showed the same growth behavior as well as the same increase in the medium $\mathrm{pH}$ for both strains.

For complementation analysis, plasmid pMAS17 harboring the complete $e m r R$ gene under the control of its own promoter region in the broad-host range vector pPHU231 was constructed. In trans complementation of the $\Delta e m r R$ mutant with pMAS17 restored growth in GMS medium as well as the $\mathrm{pH}$ profile of the culture medium to the wild-type level (Fig. 2A).

To determine if the $\Delta e m r R$ mutant was more sensitive to acidic $\mathrm{pH}$, cells were exposed to an acid shift and growth behavior was monitored. At $\mathrm{pH} 5.0$ and below, none of the strains were growing. At $\mathrm{pH} 5.5$, the $\Delta e m r R$ mutant grew more poorly than Sm1021, although it still exhibited considerable growth and this phenotypic defect could be complemented by expressing the emrR gene from pMAS17 (Fig. 2C). pH measurement of the culture supernatant during a time period of 4 days showed a slight increase for the $\Delta e m r R$ mutant, while the Sm1021 wild-type and the complemented mutant were able to increase the $\mathrm{pH}$ value by approximately 1 unit (Fig. 2C). When the medium was buffered with morpholineethanesulfonic acid ( $\mathrm{pH} 5.5)$, there was no growth difference between the $\Delta e m r R$ mutant and the wild-type strain, with both strains growing poorly (data not shown).

The previous GMS culture medium acidification by the $\Delta e m r R$ mutant suggests that this strain secretes one or more products of an acidic nature. To test whether this phenotype was dependent on the presence of the EmrAB MFS transporter, a double mutant $\triangle e m r A R$ was tested for growth in the different media and for external $\mathrm{pH}$ variation. The double mutant behaved as the wild-type strain under all tested growth conditions (data not shown), suggesting that the negative effect on growth and medium acidification caused by the absence of EmrR was suppressed by additional inactivation of the MFStransporter encoding gene. It is important to say that the $\triangle e m r A R$ double mutant is effectively a triple mutant, since the $e m r B$ gene cannot be expressed due to the absence of the $e m r A B$ promoter region. Nevertheless, it will be referred to in this text as a double mutant, since only the region spanning the beginning of $e m r A$ until the end of $e m r R$ was deleted.

\section{Loss of emrR function strongly decreases competitive nodulation ability of $S$. meliloti.}

To examine the symbiotic phenotype of the $\Delta e m r R$ deletion mutant, plant inoculation experiments were performed in agar plates on the host plant Medicago sativa. After 4 weeks, plants inoculated with the wild-type Sm1021 were healthy, with an average number of approximately four nodules per plant, whereas the plants inoculated with the $\Delta e m r R$ mutant were
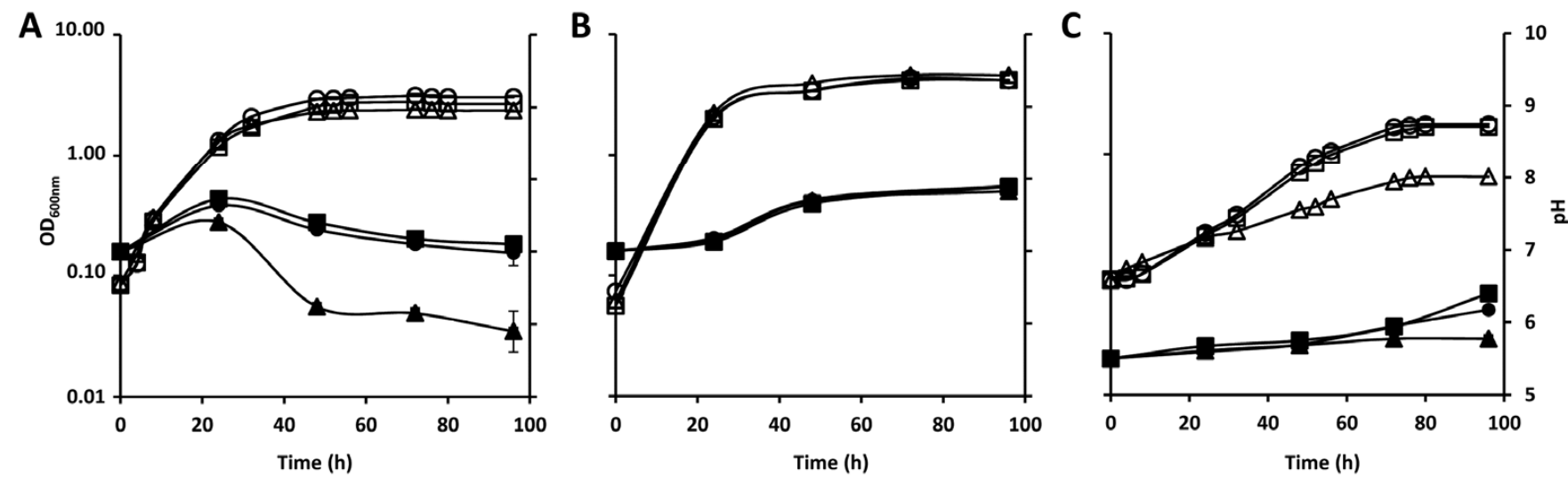

Fig. 2. Growth curves of Sinorhizobium meliloti strains as estimated by optical density at $600 \mathrm{~nm}$ during a 96-h period at $30^{\circ} \mathrm{C}$ (open symbols) and fluctuation of the $\mathrm{pH}$ culture supernatant (filled symbols) of cells growing in $\mathbf{A}$, glutamate-mannitol salts (GMS) medium at $\mathrm{pH}$ 7, $\mathbf{B}$, morpholinepropanesulfonic

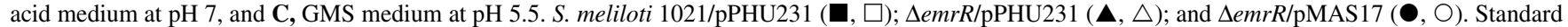
deviation of the growth curves is below $5 \%$. $\mathrm{pH}$ values are the mean \pm standard deviation of at least three independent experiments.
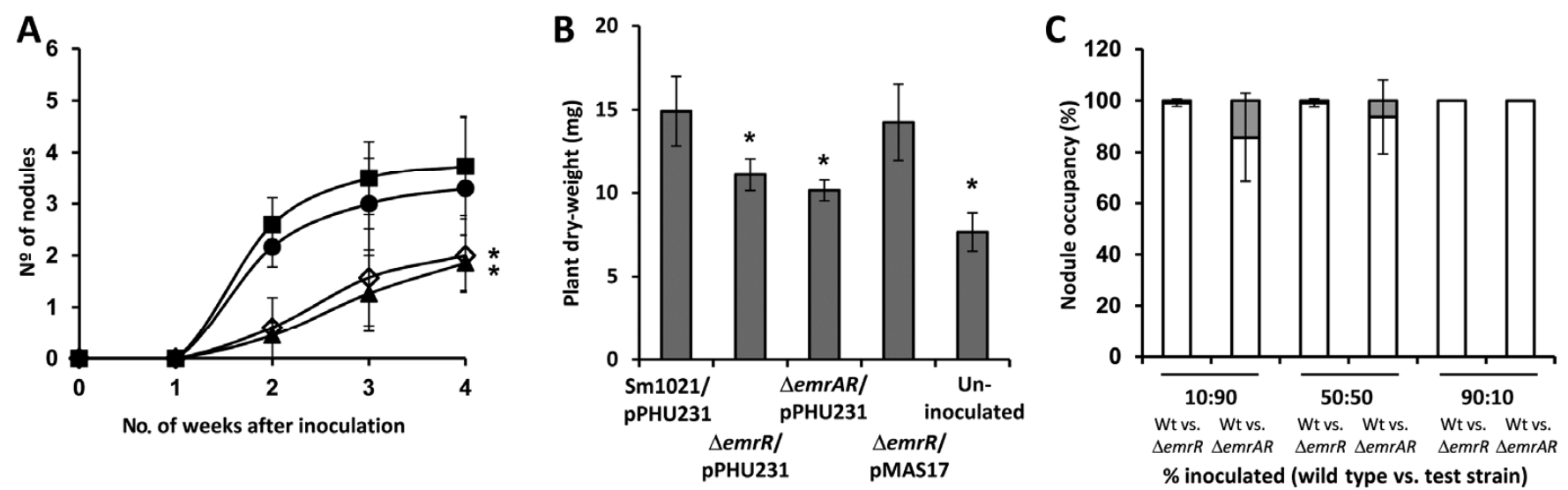

Fig. 3. A, Rate of root nodules induced by strains Sm1021/pPHU231 (ם), $\Delta e m r R / p P H U 231(\boldsymbol{\Delta}), \Delta e m r A R / p P H U 231(\diamond)$, and $\Delta e m r R$ complemented in trans with plasmid pMAS17 expressing the $\operatorname{emrR}$ gene (O). B, Plant dry weight determined 4 weeks postinoculation with the indicated bacteria. C, Competition for nodule occupancy between the wild-type strain Sm1021 (white bars) and the $\Delta e m r R$ mutant or the $\Delta e m r A R$ double mutant (gray bars). Values are the mean \pm standard deviation of at least three independent experiments. A $P$ value $<0.05$ was considered significant compared with Sm1021/pPHU231 $(*)$. 
smaller with an average number of two nodules per plant (Fig. 3A). Plant dry-weight determination confirmed a reduction of growth by approximately $25 \%$ when inoculated with the $\Delta e m r R$ mutant (Fig. 3B). Nevertheless, this value is $30 \%$ higher than the uninoculated plants, implying that the $\Delta e m r R$ mutant is $\mathrm{Fix}^{+}$. The symbiotic defective phenotype of $\Delta e m r R$ mutant was complemented by the introduction of pMAS17. Pink nodule crush from plants inoculated with the $\Delta e m r R$ mutant followed by bacterial plating in TY media confirmed that these nodules were colonized by mutant cells in numbers that did not differ significantly from wild-type levels (data not shown). The symbiotic phenotype of the $\triangle e m r A R$ mutant was similar to the one of the $\Delta e m r R$ mutant, both for induced nodule number and plant size (Figs. 3A and B).

Due to the lower amount of nodules induced by the $\Delta e m r R$ and the $\triangle e m r A R$ mutant strains, we performed competitive nodulation assays. For that, the wild-type strain and the mutant $\triangle e m r R$ or $\triangle e m r A R$ were combined at a 1:9,1:1, and 9:1 ratio and were then applied onto $M$. sativa roots. Four weeks after inoculation, bacteria were re-isolated from nodules, and more than $85 \%$ of the analyzed colonies corresponded to the wildtype, independently of the proportion tested (Fig. 3C). These results suggest that the absence of the $e m r R$ gene in both mutants interferes with their ability to establish a full symbiosis.

\section{Deletion of $e m r R$ has consequences}

in motility, biofilm formation, and adhesion to roots.

To evaluate if the lower competitive ability of the $\Delta e m r R$ and $\triangle e m r A R$ mutants is caused by some delay in the early steps of symbiotic establishment, we quantified motility, biofilm formation, and root-hair attachment. To mimic symbiotic conditions, motility and biofilm formation were tested in the presence of luteolin, known to induce the expression of the emrR gene (Capela et al. 2005). As regards swimming motility, the $\Delta e m r R$ mutant showed a slightly lower motility than the wild-type strain Sm1021, restored by the introduction of plasmid pMAS7 (Fig. 4A). The double mutant $\triangle e m r A R$ was as motile as the wild-type strain. Due to the shape of colony ramifications, it was not possible to quantify swarming motility. Nevertheless, a different colony shape of $\Delta e m r R$ mutant was
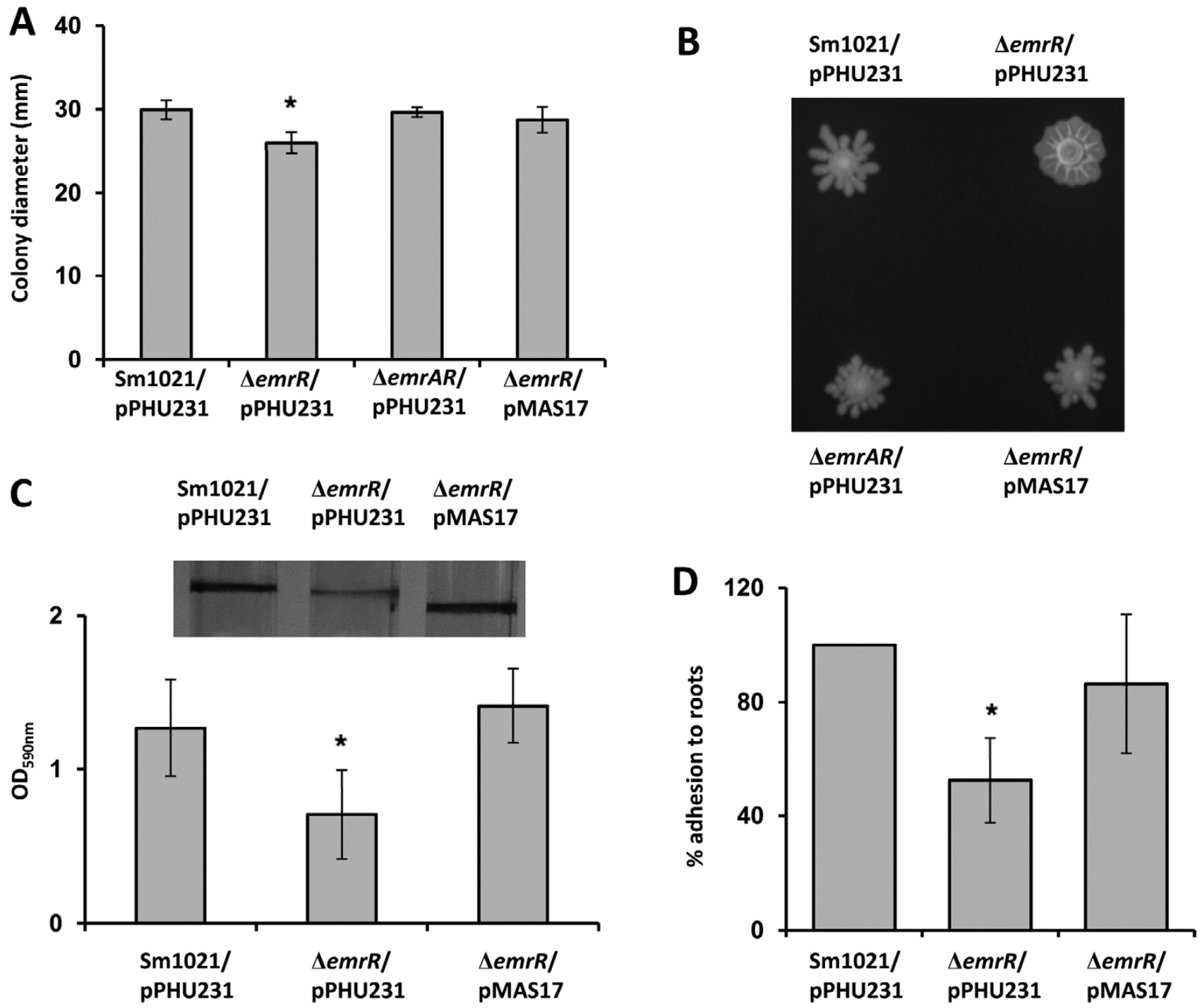

Fig. 4. Motility and adhesion properties of Sinorhizobium meliloti $1021 \Delta e m r R$ mutant. A, Swimming motility measured by the colony diameter obtained after 3 days of incubation in $0.3 \%$ purified agar glutamate-mannitol salts (GMS) medium supplemented with luteolin at $30^{\circ} \mathrm{C} ; \mathbf{B}$, Swarming motility obtained after $48 \mathrm{~h}$ of incubation in $0.6 \%$ purified agar GMS medium supplemented with luteolin at $30^{\circ} \mathrm{C} ; \mathbf{C}$, Biofilm formation measured by crystal violet staining assay using static broth cultures. Bacteria were cultured in test tubes with Vincent medium supplemented with luteolin for $72 \mathrm{~h}$ at $30^{\circ} \mathrm{C}$. An image of the biofilm formed at the liquid and air interface before crystal violet solubilization is also shown. D, Root-hair attachment by bacteria as determined by CFU count after $8 \mathrm{~h}$ of incubation. The percentage of attachment for the $\Delta e m r R$ mutant and complemented mutant are relative to the wild-type strain, considered $100 \%$. Values are the mean \pm standard deviation of at least three independent experiments. A $P$ value $<0.05$ was considered significant compared with Sm1021/pPHU231 (*). 
observed in comparison with the wild-type Sm1021, the complemented mutant, and the $\triangle e m r A R$ deletion mutant (Fig. 4B). We then measured biofilm formation in glass test tubes containing $3 \mathrm{ml}$ of Vincent medium supplemented with $10 \mu \mathrm{M}$ luteolin and incubated at $30^{\circ} \mathrm{C}$ for 3 days. After removal of the liquid culture and the washing steps, the biofilm formed at the liquid and air interface (Fig. 4C) was quantified. Data obtained indicated that the final biomass was reduced in the $\Delta e m r R \mathrm{mu}-$ tant in comparison with the wild-type strain and the $\Delta e m r R$ complemented mutant (Fig. 4C). This difference in biofilm formation of the $\Delta e m r R$ mutant may be indicative of different attachment to surfaces. Therefore, we analyzed the attachment of $\Delta e m r R$ mutant to roots using seedlings of the host plant $M$. sativa by co-incubating bacteria and roots in nitrogen-free medium as previously described (Rolfe et al. 1980) for $8 \mathrm{~h}$. After this time, seedlings were washed to remove unbound bacteria and were vortexed to release attached bacteria into solution, followed by plating into TY solid medium. A CFU count indicated a reduction of about $50 \%$ in the number of attached bacteria of the $\Delta e m r R$ mutant when compared with the wild-type strain (Fig. 4D). Complementation of the mutant with the emrR gene from pMAS17 restored adhesion to levels close to the wild-type Sm1021 strain. To exclude a negative effect of the nitrogen-free medium in cell viability and root attachment, CFU of the $\Delta e m r R$ mutant and wild-type strain at the beginning and after $8 \mathrm{~h}$ of incubation without a root were determined. During the tested period no significant differences were obtained in colony number of each strain (data not shown), suggesting that the reduced adhesion of $\Delta e m r R$ mutant to roots is not caused by loss of cell viability.

\section{Identification of altered pathways in the $\Delta e m r R$ mutant.}

Due to the symbiotic impairment of the $\Delta e m r R$, we performed a transcriptional analysis of three biological replicates of wild-type $S$. meliloti 1021 and the $\Delta e m r R$ deletion mutant grown in GMS medium supplemented with $10 \mu \mathrm{M}$ luteolin for $4 \mathrm{~h}$. Comparison of the transcriptome of the $\Delta e m r R$ deletion mutant with the one of the wild-type strain using a lower confidence bound fold change cutoff of 1.2 resulted in 285 genes differentially expressed, with a false discovery rate (FDR) of $\leq 0.9 \%$, in which 172 genes showed increased levels of expression and 113 genes showed decreased levels of expression (Supplementary Table S1). Replicon distribution of the 285 emrR-dependent differentially expressed genes indicated that $59 \%$ were chromosomal, $22 \%$ from pSymB, and $19 \%$ from pSymA, which corresponds to approximately $5 \%$ of the genes

Table 1. Quantitative real-time reverse transcription-polymerase chain reaction analysis performed in Sinorhizobium meliloti 1021 and $\Delta e m r R$ mutant cells

\begin{tabular}{lcc}
\hline Gene identifier (gene name) & LB-FC & Real-time fold change $^{\mathbf{b}}$ \\
\hline SMa0869 (nodA) & -1.6 & $-1.7 \pm 0.5$ \\
SMa1442 & 1.7 & $7.5 \pm 1.6$ \\
SMa2402 (rhbB) & -1.3 & $-1.5 \pm 0.2$ \\
SMb20198 (rbcL) & 1.4 & $4.1 \pm 1.2$ \\
SMb20961 (exoP) & 1.9 & $2.7 \pm 1.3$ \\
SMb21174 (phoT) & -2.6 & $-4.6 \pm 2.4$ \\
SMb21191 (msbA2) & 1.6 & $2.9 \pm 1.3$ \\
SMc00168 (sinI) & 1.2 & $2.5 \pm 1.0$ \\
SMc00646 (rpoH1) & -1.3 & $-1.5 \pm 0.3$ \\
SMc00658 & 1.6 & $4.1 \pm 0.8$ \\
SMc00913 (groEL1) & -1.4 & $-1.5 \pm 0.3$ \\
SMc01944 (cpo) & -1.3 & $-1.6 \pm 0.3$ \\
SMc02560 (chvI) & 1.6 & $4.5 \pm 2.3$ \\
SMc03170 & 3.4 & $5.4 \pm 2.1$ \\
SMc04267 (lps $)$ & 1.6 & $4.1 \pm 1.7$ \\
\hline
\end{tabular}

\footnotetext{
${ }^{a}$ Microarray lower bound of fold change.
}

${ }^{\mathrm{b}}$ Fold change \pm standard deviation. present in each replicon. The distribution of genes by functional groups showed a significant decrease in the expression of genes related to symbiotic signaling, stress response, and inorganic ion transport and metabolism. In contrast, the expression level of genes encoding transcriptional regulators, energy conversion, and metabolism as well as cell envelope biogenesis was increased in the $\Delta e m r R$ mutant transcriptome. As a validation of the microarray data, the expression of several genes was measured by quantitative reverse transcription-polymerase chain reaction (qRT-PCR) (Table 1). The expression values are in good agreement with the microarray data.

\section{Genes with increased expression in the $\Delta e m r R$ deletion mutant.}

Genes with the highest value of fold change are located in the vicinity of gene $e m r R$. These include downstream the putative AraC family transcription regulator $S M c 03170$ (3.4-fold) and upstream the genes $e m r A$ and $e m r B$ (3.8- and 3.6-fold, respectively), and the putative metallophosphoesterase encoding gene $S M c 03166$, with an increased expression of 7.3-fold in the $\Delta e m r R$ mutant when compared with the wild-type Sm1021 strain. Most likely the expression of those genes is repressed when protein EmrR is present and, therefore, the putative promoter regions of SMc03170, emrA, and SMc03166 genes are good targets for the direct binding of EmrR protein.

Another gene with increased expression in the $\Delta e m r R \mathrm{mu}-$ tant encodes the transcriptional regulator ChvI (1.6-fold). This regulator is known to be involved in polysaccharide biosynthesis, motility, and metabolism (Bélanger et al. 2009; Chen et al. 2009; Wang et al. 2010), and many of the genes identified as ChvI targets (Chen et al. 2009) showed increased expression in our microarray data set. These include all the exo genes involved in succinoglycan biosynthesis (Reuber and Walker 1993; Reuber et al. 1991), the $m s b A 2$ operon ( $S M b 21188$ to $S M b 21191)$ also involved in polysaccharide biosynthesis and symbiosis (Beck et al. 2008; Bélanger and Charles 2013), the sinI gene encoding the $N$-acyl-L-homoserine lactone synthetase, the ropBl gene encoding an outer membrane protein that influences phage sensitivity of $S$. meliloti (Campbell et al. 2003), and several other genes of unknown function, such as $S M c 01580$ and $S M b 21440$, whose intergenic upstream regions were demonstrated as direct binding sites of the ChvI regulator (Chen et al. 2009). To determine whether the increased expression of the exo genes had influence on the amount of succinoglycan produced, the wild-type Sm1021, the $\Delta e m r R$ and $\triangle e m r A R$ deletion mutants, and the complemented $\Delta e m r R$ mutant strain were grown for 10 days in GMS medium supplemented with luteolin, followed by cell-free supernatant precipitation. The results shown in Figure 5 confirmed that, in the $\Delta e m r R$ mutant, the amount of total carbohydrates present in the cetyl pyridinium chloride (CPC)-precipitated supernatant was much higher than the one for the wild-type and complemented mutant. The double mutant $\triangle e m r A R$ produced similar amount of carbohydrates as the wild-type strain (Fig. 5). To confirm the nature of this polysaccharide as being succinoglycan, an exoY mutation was transduced to Sm1021, $\Delta$ emrR mutant, and $\triangle e m r A R$ double mutant. These Sm1021 exoY-lacZ/aacC1, $\Delta e m r R$ exoY-lacZ/aacCl, and $\triangle$ emrAR exoY-lacZ/aacCl CPCprecipitated culture supernatants showed a very low amount of total carbohydrates (less than $2 \mathrm{mg}$ of glucose equivalents per liter after 10 days of growth), confirming the absence of succinoglycan (Fig. 5).

\section{Genes with decreased expression} in the $\Delta e m r R$ deletion mutant.

Among the genes displaying decreased expression in the $\Delta e m r R$ deletion mutant when compared with the Sm1021 
wild-type strain are sixteen nod and noe genes involved in Nod factor biosynthesis. None of these genes encodes a transcriptional regulator of the NodD family whose activity positively controls nod, nol, and noe gene expression, and the process by which protein EmrR affects nod and noe gene expression is unknown. Nevertheless, the comparison of the differentially expressed genes between the data sets $\Delta e m r R$ mutant vs. wildtype and nodD1 mutant vs. wild-type (Capela et al. 2005) obtained in the presence of luteolin showed 31 genes in common. The common genes with decreased expression were the nol, nod, groEL5, and ibpA genes and the ones with increased expression were SMa1809 and SMa1821, encoding a nonheme haloperoxidase and a hydrolase, respectively, SMc02446, encoding a putative pilus assembly protein, and $e d d$, encoding a phopophogluconate dehydratase.

Another set of genes with differential expression are the ones involved in iron and phosphate acquisition. Under iron limitation, $S$. meliloti produces the siderophore rhizobactin (Lynch et al. 2001). Here, we observed that the genes $r h b B$, $r h b C, r h b D, r h b E, r h b F, r h t A$, and $S M a 2339$ had a decreased expression in the $\Delta e m r R$ mutant strain. To assess whether the decreased expression of those genes had a negative effect on the $\Delta e m r R$ mutant growth under iron limitation, two different assays were performed. In one of them, Sm1021 wild-type, the $\Delta e m r R$ mutant, and the complemented mutant, grown overnight in GMS medium, were spot-inoculated onto GMS-chrome azurol S (CAS) medium and were incubated for 3 days. Under these conditions, the wild-type strain and complemented mutant formed a colony with an orange halo due to siderophore diffusion and iron chelation, while the $\Delta e m r R$ mutant strain was unable to grow (Fig. 6A). The $\triangle e m r A R$ mutant showed a siderophore production identical to the wild-type strain (data not shown). In the second approach, cells were grown in GMS supplemented with $175 \mu \mathrm{M}$ of the iron chelating agent dipyridyl. As seen in Figure 6B, there was a negative effect on the growth of the $\Delta e m r R$ deletion mutant, as this strain most likely produced a lower amount of siderophores, while Sm1021 and the complemented mutant presented higher growth rate.

Genes showing the greatest decrease in expression encode the high-affinity phosphate uptake ABC transporter PhoCDET (2.3 to 3.0-fold). To determine whether the $\Delta e m r R$ deletion

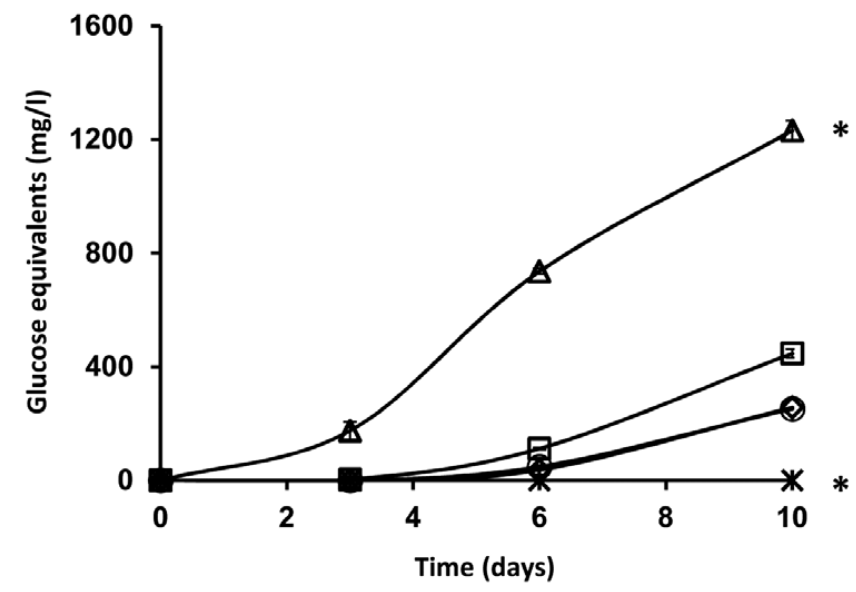

Fig. 5. Exopolysaccharide production assessed by measuring the total carbohydrates content of the cetyl pyridinium chloride-precipitate obtained from growing Sinorhizobium meliloti 1021/pPHU231 ( $\square$ ), the $\Delta e m r R /$ pPHU231 mutant $(\triangle)$, the complemented mutant $\Delta e m r R /$ pMAS17 (O), the $\triangle e m r A R$ double mutant $(\diamond)$, and the $\Delta e m r R$ exoY/pPHU231 mutant (Ж) in GMS medium containing $10 \mu \mathrm{M}$ luteolin at $30^{\circ} \mathrm{C}$ for 10 days Values are the mean \pm standard deviation of at least three independent experiments. A $P$ value $<0.05$ was considered significant compared with Sm1021/pPHU231 (*). mutant had a growth defect under phosphate limitation, it was grown in GMS medium without addition of phosphate or supplemented with 0.05 and $1.0 \mathrm{mM}$. Results showed no difference between the $\Delta e m r R$ mutant and the wild-type strain for each of the tested phosphate concentrations (data not shown).

Another gene with a decreased level of expression was rpoH1, encoding the alternative sigma factor RpoH1. The comparison between our expression data and those obtained for the S. meliloti $1021 \mathrm{rpoH}$ l deletion mutant under acidic $\mathrm{pH}$ stress (de Lucena et al. 2010) and heat-shock (Barnett et al. 2012) showed seven genes in common. Genes with increased expression encode a D-3-phosphoglycerate dehydrogenase, SerA, a putative membrane-bound lytic transglycosylase, SMc01855, and the beta subunit of glutamate synthase GltD. Genes with decreased expression were $S M b 21295$ and SMb21566, encoding a Hsp20 family heat-shock protein and a GroEL5 chaperonine, respectively, SMc00591, encoding a hypothetical protein, and $i b p A$, encoding another heat-shock protein. Despite this limited overlap between the three datasets, we have shown the increased sensitivity of the $\Delta e m r R$ mutant under acidic condition (Fig. 2). To expand this analysis, we also tested heat and osmotic shocks and oxidative stress. Heat-shock response was tested by incubating exponential growth-phase cultures (grown for $4 \mathrm{~h}$ in GMS medium supplemented with $10 \mu \mathrm{M}$ luteolin) for 15 and $30 \mathrm{~min}$ at 42 and $30^{\circ} \mathrm{C}$, followed by $\mathrm{CFU}$ determination. Viability at $42^{\circ} \mathrm{C}$ was compared with $30^{\circ} \mathrm{C}$, a non-heat shock temperature used as control. Results showed an increased survival at $42^{\circ} \mathrm{C}$ of the $\Delta e m r R$ mutant at both time points when compared with the wild-type strain (Fig. 7A). In contrast, the double $\triangle e m r A R$ mutant showed the lowest

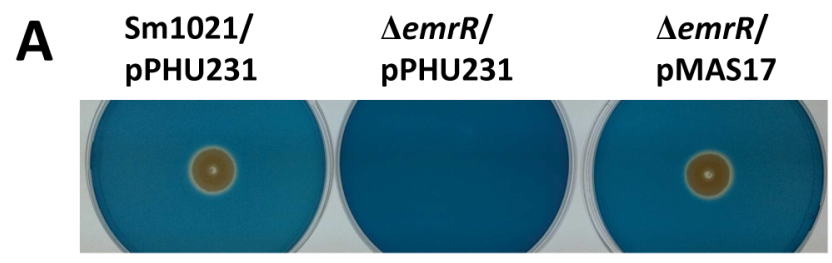

B 10

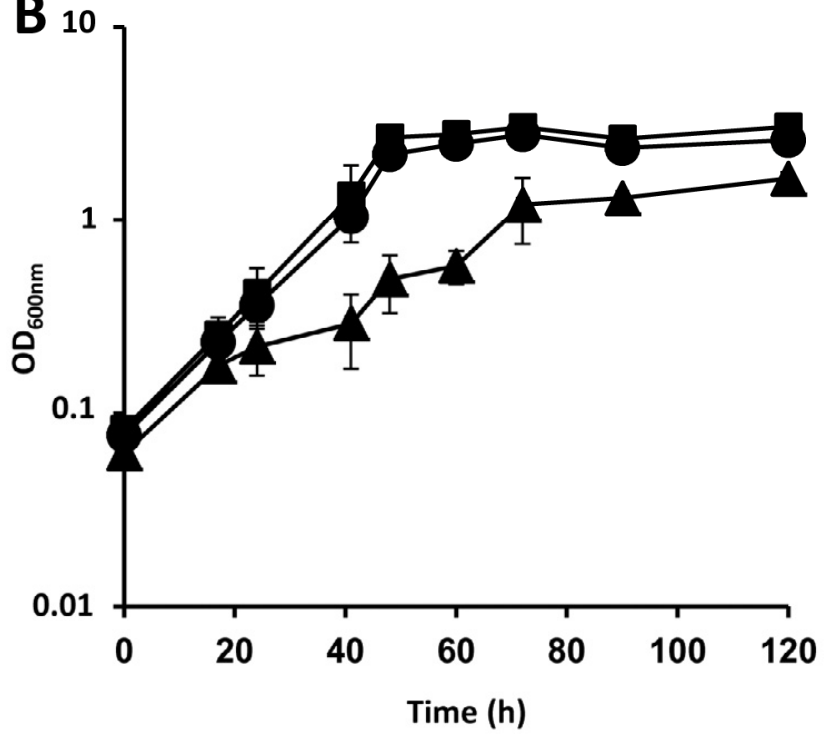

Fig. 6. A, Siderophore production by Sinorhizobium meliloti strains assayed in glutamate-mannitol salts (GMS)-chrome azurol S agar plates spotted with $10 \mu \mathrm{l}$ of bacteria and incubated at $30^{\circ} \mathrm{C}$ for 3 days. B, Growth curve of Sm1021/pPHU231 (ם), $\Delta e m r R / p P H U 231$ ( $\mathbf{\Delta})$, and $\Delta e m r R$ mutant complemented in trans with plasmid pMAS17 expressing the $e m r R$ gene (O) in GMS medium supplemented with $175 \mu \mathrm{M}$ of dipyridyl as estimated by optical density measurement at $30^{\circ} \mathrm{C}$. Values are the mean \pm standard deviation of at least three independent experiments. 
survival ability under heat shock, followed by the complemented $\Delta$ emrR mutant (Fig. 7A).

Osmotic shock was tested by adding $0.3 \mathrm{M}$ of $\mathrm{NaCl}$ to the GMS medium used for growing strains, but no difference in growth behavior was observed (data not shown). Resistance against oxidative stress was tested in the presence of $1 \mathrm{M}$ hydrogen peroxide. Results indicated that the $\Delta e m r R$ mutant was slightly more sensitive to this compound than the other tested strains (Fig. 7B).

In addition, we also evaluated the sensitivity of the $\Delta e m r R$ deletion mutant to malachite green and crystal violet, two lipophilic inhibitors of cell growth that have been used to screen for cell-wall perturbations, and the anionic detergent SDS. As seen in Figure 7B, cells deleted for the $e m r R$ gene showed higher sensitivity than the wild-type Sm1021 and the double $\triangle e m r A R$ mutant to all the tested compounds, implying differences in membrane integrity of this mutant. The introduction of pMAS17 into the $\Delta e m r R$ deletion mutant rescued the phenotype to wild-type levels. These results suggest that EmrR protein may play a role in maintaining membrane stability during stress conditions.

\section{DISCUSSION}

In the current study, we characterized the emrR gene encoding a putative transcriptional repressor of the TetR family and the neighbor genes $e m r A$ and $e m r B$, encoding a putative MFStype transporter. Deletion of the $e m r B$ gene had no significant impact in $S$. meliloti physiology, but the absence of the EmrR regulator caused alteration of cellular properties, such as motility, membrane permeability, siderophore production, adhesion to biotic and abiotic surfaces, polysaccharide production, acidic and heat shock responses, and competitive nodulation efficiency. Interestingly, the simultaneous deletion of emrA and emrR genes restored all the phenotypes to wild-type levels, except for the symbiotic properties and survival under heat-shock conditions. These observations suggest that most of the freeliving $\Delta e m r R$ phenotypes and microarray expression data are a pleiotropic consequence of aberrant expression of genes $e m r A$, $e m r B$, and $S M c 03166$. The most frequent function performed by TetR family proteins is the regulation of efflux pumps and transporters involved in antibiotic resistance and tolerance to toxic chemicals, but some others participate in regulatory networks involved in metabolism homeostasis, osmotic stress, quorum sensing, biosynthesis of antibiotics, and pathogenicity
(Cuthbertson and Nodwell 2013; Ramos et al. 2005). One of the most studied MFS-type transporters is the E. coli AcrABTolC efflux transporter leading to a multiple antibiotic resistance phenotype (Okusu et al. 1996). The acrA and $a c r B$ genes form an operon whose transcription is regulated by the product of the divergently transcribed $a c r R$ gene encoding a transcriptional repressor of the TetR family (Ma et al. 1996). Similarly, $S$. meliloti emrR gene is transcribed in the opposite direction of genes $e m r A$ and $e m r B$ and these genes are targets for EmrR repression. In fact, the expression data confirmed that in the absence of EmrR, the genes $e m r A$ and $e m r B$ had increased expression, suggesting a possible repression in the presence of EmrR. Also, gene SMc03166, encoding a putative metallophosphoesterase, and $S M c 03170$, encoding a putative regulator of the AraC family, showed increased expression. Thus, it is very likely that these genes act together. Perhaps, in the presence of the EmrR protein, the expression of SMc03166, $e m r A B$, and $S M c 03170$ genes is repressed, but in its absence, they could be expressed directly or indirectly through activation by the SMc03170 transcriptional regulator. This needs to be experimentally determined.

The expression of $S$. meliloti emrAB genes has been shown to increase under heat shock (Barnett et al. 2012), acidic pH shift (de Lucena et al. 2010), in the absence of a functional TolC protein (Santos et al. 2010), in the presence of luteolin (Barnett et al. 2004; Capela et al. 2005), and in mature nodules (Barnett et al. 2004), and it has been shown to decrease in the exoR mutant (Wells et al. 2007). As the above stresses have strong effect on the cell envelope, it is possible that emrAB is important in response to stresses acting on the cell envelope. In that sense, the increased expression of $e m r A B$ in the $\triangle e m r R$ mutant should have a positive effect on the response to stresses such as low $\mathrm{pH}$, osmotic stress, and heat shock. At least for heat-shock conditions, that positive effect on survival of the $\Delta e m r R$ deletion mutant was observed. Additionally, the simultaneous deletion of emrR and $e m r A$ genes had a negative effect on survival, suggesting that the MFS transporter EmrAB is required under heat shock. This observation is further supported by the low survival rate of the complemented $\Delta e m r R$ mutant. The overexpression of the EmrR repressor in this strain must decrease the expression levels of $e m r A B$ genes and, consequently, cells have increased deficiency in mounting a heat-shock response. The comparison between our expression data and those obtained for acidic $\mathrm{pH}$ (de Lucena et al. 2010) and heat shock (Barnett et al. 2012) have in common the increased expression of the chvI gene encoding
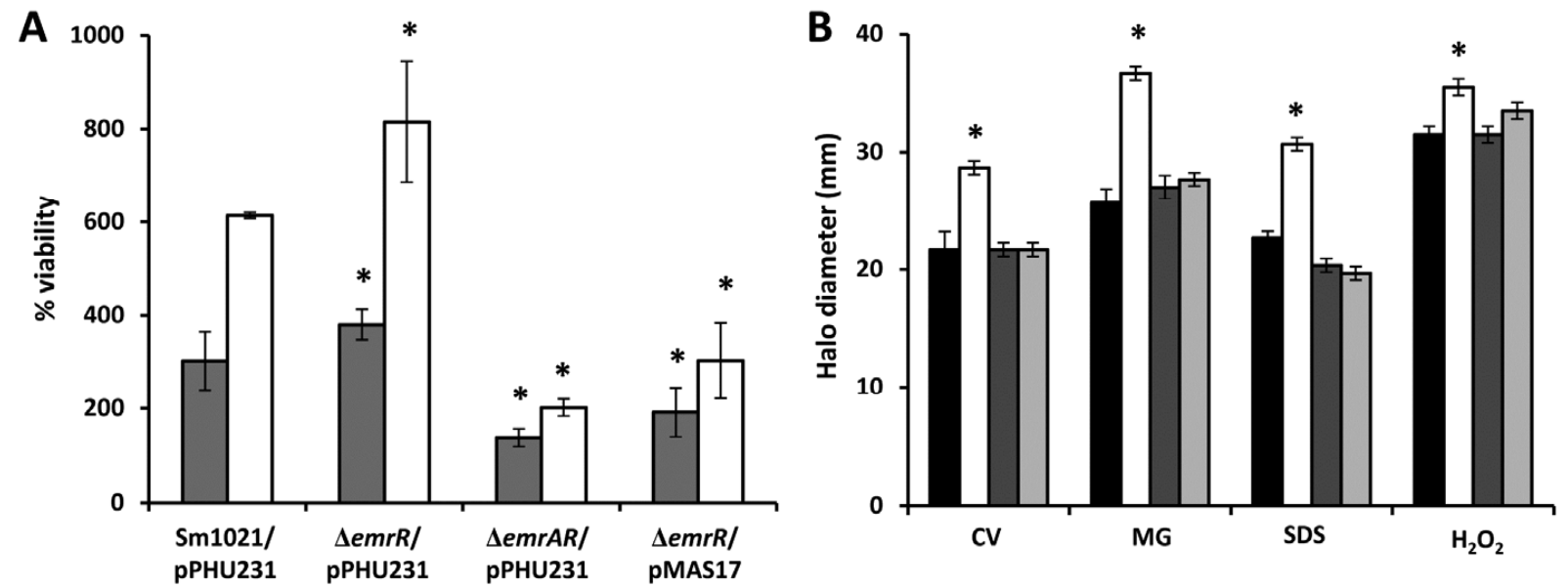

- Sm1021/ pPHU231

$\Delta e m r R /$ pPHU231

口 $\triangle$ EmrAR/ PPHU231

$\Delta e m r R /$ pMAS17

Fig. 7. Survival of Sinorhizobium meliloti strains under stress conditions. A, Cell viability at $42^{\circ} \mathrm{C}$ when compared to $30^{\circ} \mathrm{C}$ after $15 \mathrm{~min}$ (gray bars) and 30 min (white bars) of exposure as determined by CFU count. B, Sensitivity to stress-inducing agents (1\% crystal violet [CV], 5\% malachite green [MG], 10\% sodium dodecyl sulfate [SDS], and $1 \mathrm{M} \mathrm{H}_{2} \mathrm{O}_{2}$ ) determined by measuring growth-inhibition haloes after incubation of plates at $30^{\circ} \mathrm{C}$ for 3 days. Values are the mean \pm standard deviation of at least three independent experiments. A $P$ value $<0.05$ was considered significant compared with Sm1021/pPHU231 (*). 
the response regulator of $S$. meliloti $\mathrm{ChvG}(\mathrm{ExoS}) / \mathrm{ChvI}$ twocomponent regulatory system (Bélanger et al. 2009; Wang et al. 2010), the exo genes directing the biosynthesis of succinoglycan (Leigh and Lee 1988), lpsS gene encoding a sulfotransferase involved in LPS modification (Cronan and Keating 2004), and other genes with unknown function, such as $S M b 21440$ or $S M c 02278$. Genes with decreased expression in the $\Delta e m r R$ mutant, whose products are involved in rhizobactin biosynthesis (Lynch et al. 2001), sulfur assimilation (Abola et al. 1999), and synthesis of phosphorus-free membrane lipids (López-Lara et al. 2005), were common to the osmotic and heat-shock gene expression datasets (Barnett et al. 2012; de Lucena et al. 2010). From this analysis is evident that the $\Delta e m r R$ mutant is under stress and the displayed phenotypes are most likely due to overexpression of the adjacent genes. It remains to be determined whether that stress is caused by extra copies of EmrAB proteins at the membrane or is caused by excessive hydrolysis of the SMc03166 substrate and secretion, possibly mediated by EmrAB transporter.

One of the most evident phenotypes displayed by the $\Delta e m r R$ deletion mutant is overproduction of succinoglycan. Although speculative, that increase in succinoglycan could explain the decrease in biomass observed in GMS medium when cells enter stationary phase and perhaps the acidification of the growth medium. Overproduction of succinoglycan may imply an increase in nutrient uptake and in the precursor's formation, namely the activated nucleotide sugars and the acetyl, pyruvyl, and succinyl modifications. These needs are reflected in the expression data by the increased expression of the exo genes, the $d c t A$ gene encoding the C4-dicarboxylate transporter, and several genes involved in the biosynthesis of tricarboxylic acid cycle enzymes, namely sucA, $s u c B$, sucC, sucD, and $m d h$. Besides the $\Delta e m r R$ mutant, other mutants are known to overproduce succinoglycan, namely the mutants with a Tn5 insertion in exoS and exoR genes (Cheng and Walker 1998), the podJ mutant (Fields et al. 2012), the cbrA mutant (Gibson et al. 2006), and the emmABC mutant (Morris and González 2009). As these mutants also shared other phenotypes, such as decreased motility, have cell-envelope defects, and are impaired in symbiosis, the increase in succinoglycan production can be a response to cell-envelope deficiency, or EPS production and cell-envelope integrity share common regulatory pathways.

Previous transcriptomic analysis of the wild-type $S$. meliloti in the presence of luteolin showed increased expression of $e m r A B$ and $e m r R$ genes when compared with the noninducing condition (Barnett et al. 2004; Capela et al. 2005). In addition, emrA expression was induced in bacteroids (Barnett et al. 2004). Our work shows the importance of EmrR in symbiosis, as both the $\triangle e m r R$ and the $\triangle e m r A R$ mutants, despite being $\mathrm{Fix}^{+}$, showed reduced nodule formation and reduced competitiveness against the wild-type strain in coinoculation experiments. Considering that overexpression of emrA (through the deletion of $e m r R$ gene) and the deletion of $e m r A$ (as part of the emrAR deletion) have the same symbiotic phenotype, it excludes the idea of the EmrAB MFS transporter having an important role in symbiosis. Therefore, it could be that the main function of EmrR is to mount a response to stress caused by the presence of luteolin or a derived compound. In E. coli, luteolin seems to have a negative effect in protein and peptide synthesis and in alteration of inner and outer membrane permeability (Eumkeb et al. 2012). Perhaps in the presence of this compound, $S$. meliloti cells need to restructure the cell envelope, possibly mediated by the putative metallophosphoesterase SMc03166 protein. Whether the symbiotic defect of the $\Delta e m r R$ and of the $\triangle e m r A R$ mutants can be due to overexpression of the $S M c 03166$ gene product still needs to be determined, but that could explain why the emrR symbiotic phenotype is not relieved with the additional mutation of the emrA gene.

In conclusion, this work suggests that when $S$. meliloti is in the presence of flavonoids, a gene expression program is put into action to produce the signaling molecule Nod factors but, also, to adjust metabolic functions and cell-envelope composition. One possible mechanism is through the release of EmrR repressor from certain promoters and directly or indirectly activating the expression of genes involved in either stress response or cell-wall composition or both while repressing polysaccharide biosynthesis, perhaps exposing cellular structures important for adhesion and invasion of plant root hairs. Because

Table 2. Strains, plasmids, and phage used in this study

\begin{tabular}{|c|c|c|}
\hline Strain or plasmid & Relevant characteristics $^{\mathrm{a}}$ & Source/reference \\
\hline \multicolumn{3}{|l|}{ Bacterial strains } \\
\hline \multicolumn{3}{|c|}{ Sinorhizobium meliloti } \\
\hline Sm1021 & Wild-type, $\mathrm{Su} 47, \mathrm{Sm}^{\mathrm{r}}$ & Meade et al. 1982 \\
\hline Sm1021-9 & $\mathrm{Sm} 1021 \Delta e m r R, \mathrm{Sm}^{\mathrm{r}}$ & This work \\
\hline Sm1021-7 & $\mathrm{Sm} 1021 \Delta e m r B, \mathrm{Sm}^{\mathrm{r}}$ & This work \\
\hline Sm1021-8/9 & $\mathrm{Sm} 1021 \Delta e m r A \Delta e m r R, \mathrm{Sm}^{\mathrm{r}}$ & This work \\
\hline RmAR9007 & Sm2011 exoY-lacZ/aacC1 & Keller et al. 1995 \\
\hline Sm1021Y & $\mathrm{Sm} 1021$ exoY-lacZ/aacC1, $\mathrm{Gm}^{\mathrm{r}}, \mathrm{Sm}^{\mathrm{r}}$ & This work \\
\hline Sm1021-9Y & Sm1021 AemrR exoY-lacZ/aacC1, $\mathrm{Gm}^{\mathrm{r}}, \mathrm{Sm}^{\mathrm{r}}$ & This work \\
\hline Sm1021-8/9Y & $\mathrm{Sm} 1021 \Delta e m r A \Delta e m r R$ exoY-lacZ/aacC1, $\mathrm{Gm}^{\mathrm{r}}, \mathrm{Sm}^{\mathrm{r}}$ & This work \\
\hline \multicolumn{3}{|l|}{ Escherichia coli } \\
\hline DH5 $\alpha$ & recAl $\Delta l a c \mathrm{U} 169, \varphi 80$ lacZ $\Delta \mathrm{M} 15$ & Hanahan 1983 \\
\hline S17-1 & E. coli 294 , thi $\mathrm{RP} 4-2-\mathrm{Tc}:: \mathrm{Mu}-\mathrm{Km}:: \mathrm{Tn} 7$ chromosomally integrated & Simon et al. 1983 \\
\hline \multicolumn{3}{|l|}{ Plasmids } \\
\hline pPHU231 & Broad host-range low-copy vector, $\mathrm{Tc}^{\mathrm{r}}$ & Reyes et al. 1996 \\
\hline pK19mobG & oriColE1 $\mathrm{Mob}^{+}$lac $\mathrm{Z}^{+}, \mathrm{Km}^{\mathrm{r}}$ in $E$. coli, $\mathrm{NeO}^{\mathrm{r}}$ in $S$. meliloti & Katzen et al. 1999 \\
\hline pAFM01-2 & $\begin{array}{l}\text { pK19mobG containing the } 2040 \text { and the } 2020 \text { bps fragments upstream and downstream, respectively, of } \\
\text { emrB gene, } \mathrm{Km}^{\mathrm{r}}\end{array}$ & This work \\
\hline pAFM09-2 & $\begin{array}{l}\text { pK19mobG containing the 2,223- and the 1,959-bp fragments upstream and downstream, respectively, of } \\
\text { emrR gene, } \mathrm{Km}^{\mathrm{r}}\end{array}$ & This work \\
\hline pLM135-1 & $\begin{array}{l}\text { pK19mobG containing the 2,067- and the 1,959-bp fragments upstream of } e m r A \text { and downstream of } e m r R \\
\text { genes, respectively, } \mathrm{Km}^{\mathrm{r}}\end{array}$ & This work \\
\hline pMAS17 & pPHU231 containing a 1,207-bp fragment with the emrR gene under the control of its own promoter, $\mathrm{Tc}^{\mathrm{r}}$ & This work \\
\hline \multicolumn{3}{|c|}{ 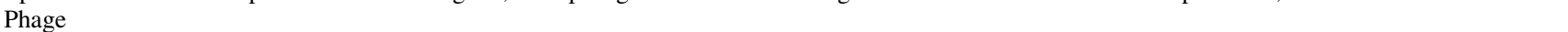 } \\
\hline$\Phi \mathrm{M} 12$ & S. meliloti transducing phage & Finan et al. 1984 \\
\hline
\end{tabular}

${ }^{\text {a }} \mathrm{Sm}^{\mathrm{r}}, \mathrm{Tc}^{\mathrm{r}}, \mathrm{Neo}^{\mathrm{r}}, \mathrm{Km}^{\mathrm{r}}$, and $\mathrm{Gm}^{\mathrm{r}}=$ streptomycin, tetracycline, neomycin, kanamycin, and gentamicin resistance, respectively. 
the early steps of symbiosis are relatively unknown and EmrR is believed to play a role in this step, further studies on the function of this TetR family regulator are justified.

\section{MATERIALS AND METHODS}

Bacterial strains and general growth conditions.

Bacterial strains and plasmids used in this study are listed in Table 2. E. coli strains were grown in Lennox Broth (Lennox $1955)$ at $37^{\circ}$ C. S. meliloti strains were grown in TY medium (Beringer 1974), MOPS buffered medium supplemented with $0.1 \mathrm{mM}$ phosphate (Neidhardt et al. 1974), or GMS medium (York and Walker 1997) at $30^{\circ} \mathrm{C}$. Starter cultures for RNA extraction were grown in TY medium and subcultured in GMS medium supplemented with $10 \mu \mathrm{M}$ luteolin. Antibiotics were supplemented as required at the following concentrations ( $\mu \mathrm{g} / \mathrm{ml})$ : for S. meliloti, streptomycin, 600; gentamicin, 40; tetracycline, 10; and neomycin, 120; for E. coli, tetracycline, 10; and kanamycin, 50. Luteolin was dissolved in 95\% dimethyl sulfoxide (DMSO) at a $4 \mathrm{mg} / \mathrm{ml}$ stock solution, and 5-bromo4-chloro-3-indoxyl- $\beta$-D-glucuronide CHA salt was dissolved in $N, N$-dimethylformamide at an $80 \mathrm{mg} / \mathrm{ml}$ stock solution. An aqueous solution of $2-2^{\prime}$ dipyridyl was used to supplement GMS medium at a final concentration of $175 \mu \mathrm{M}$. Media were solidified by the addition of $2.0 \%$ (wt/vol) agar. Liquid cultures were shaken at $180 \mathrm{rpm}$.

\section{Computational analysis of protein sequences.}

The BLAST algorithm (Altschul et al. 1997) was used to compare the deduced amino acid sequence of EmrR protein to database sequences available at the National Center for Biotechnology Information. Alignments were performed using the program CLUSTAL W (Thompson et al. 1994).

\section{DNA manipulations.}

Preparation of plasmid DNA, DNA restriction, DNA amplification, agarose gel electrophoresis, cloning, and transformation of E. coli cells were carried out according to established protocols (Sambrook and Russell 2001). Genomic DNA extraction from S. meliloti 1021 was carried out using glass beads to lyse cells, followed by purification by phenol/chloroform and precipitation with isopropanol (Sambrook and Russell 2001). Mutations were transferred between $S$. meliloti strains by phage $\Phi$ M12-mediated general transduction as described previously (Finan et al. 1984).

\section{Construction of emr gene deletion mutants.}

The flanking regions of $e m r B$ gene were amplified by PCR using S. meliloti 1021 genomic DNA as template and the oligonucleotide primers SMc03167_L (fw/rev) and SMc03167_R (fw/rev) shown in Supplementary Table S2 and were cloned into the multiple cloning site of suicide vector $\mathrm{pK} 19 \mathrm{mobG}$ (Katzen et al. 1999). The same procedure was followed for the deletion of the emrR (SMc03169) gene, but the primers used were SMc03169_L (fw/rev) and SMc03169_R (fw/rev). Deletion of emrA and $e m r R$ simultaneously was accomplished by amplifying the emrA upstream region (primers SMc03168_L (fw/rev)) and emrR downstream region SMc03169_R (fw/rev). This mutation affects the promoter region of genes emrA and $e m r B$ and, consequently, the $e m r B$ gene is not expressed. The plasmids obtained were designated pAFM01-2, pAFM09-2, and pLM135-1, characterized by deletions of emrB, emrR, and emrAR genes, respectively. These plasmids were mobilized from strain E. coli S17-1 to S. meliloti 1021. Homogenization of these mutations was carried out as previously described (Moreira et al. 2000). The mutants obtained were named

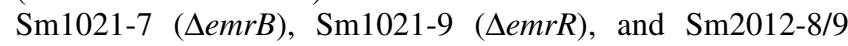

( $\triangle e m r A R$ ) (Table 2). The candidate deletion mutants were further confirmed by PCR amplification and DNA sequencing.

In order to complement the $S$. meliloti $\Delta e m r R$ deletion mutant, a 1,207-bp fragment containing the $e m r R$ gene under the control of its own promoter was amplified by PCR, using primers P03169-fw and P03169-rev and Sm1021 genomic DNA as template. The amplified fragment was inserted into the EcoRI site of broad host-range vector pPHU231, and the resulting plasmid was named pMAS17 (Table 2).

\section{Nodulation assays.}

Medicago sativa genotype Europa seeds were surfacesterilized by concentrated sulfuric acid for $10 \mathrm{~min}$ and were washed several times with large volumes of sterile water. Seeds were kept at $4{ }^{\circ} \mathrm{C}$ over a two-day period and were then allowed to germinate on $1.5 \%$ water agar plates at room temperature in the dark for $24 \mathrm{~h}$. Seedlings were then grown on nitrogen-free medium (Rolfe et al. 1980) and were inoculated with overnight cultures of $S$. meliloti strains that were washed in saline buffer. Each plate, containing three $M$. sativa seedlings, was inoculated with $200 \mu \mathrm{l}$ of cell suspension $\left(10^{8}\right.$ to $10^{9}$ cells $)$. Plants were grown under a 16-h light, 8 -h dark cycle for 4 weeks. At the end of the experiment, each plant was dried at $65^{\circ} \mathrm{C}$, until no further reduction in mass was obtained, and weighted.

In coinoculation assays, the seedlings were inoculated with a cell suspension containing different proportions of Sm1021 wild-type strain and $\triangle e m r R$ or $\triangle e m r A R$ mutants, i.e., 10:90, 50:50, and 90:10, respectively. After four weeks, nodules were harvested and crushed in TY medium as previously described (Cosme et al. 2008) and bacterial suspensions were plated on TY plates. Random colonies were tested for the presence or absence of the emrR gene by colony PCR using primers $\mathrm{SMc} 03169 \mathrm{C}-(\mathrm{fw} / \mathrm{rev})$. Briefly a colony was resuspended in 50 $\mu \mathrm{l}$ of $\mathrm{H}_{2} \mathrm{O}$ and was boiled at $100^{\circ} \mathrm{C}$ for $5 \mathrm{~min}$, followed by centrifugation. The supernatant was then used as DNA template in the PCR reaction.

\section{Motility assays.}

Motility was carried out as previously described (Soto et al. 2002). Swimming plates with $0.3 \%$ bacto agar (Difco, Detroit) and swarming plates with $0.6 \%$ Noble agar (Difco) were prepared using GMS medium supplemented with $10 \mu \mathrm{M}$ luteolin. For estimation of motility, overnight GMS cultures $(5 \mu \mathrm{l})$ were inoculated into the agar and were incubated at $30^{\circ} \mathrm{C}$ for 1 and 3 days to measure swarming and swimming motility, respectively. Three separate experiments, each containing five technical replicates, were performed.

\section{Biofilm formation.}

Bacteria were grown in Vincent minimal medium (Vincent 1970) supplemented with $10 \mu \mathrm{M}$ luteolin at $30^{\circ} \mathrm{C}$ until midexponential phase, diluted to an optical density at $600 \mathrm{~nm}$ $\left(\mathrm{OD}_{600 \mathrm{~nm}}\right)$ of 0.1 , and $3 \mathrm{ml}$ of these cell suspensions were inoculated into glass test tubes. Cell suspensions were incubated at $30^{\circ} \mathrm{C}$ without agitation for $72 \mathrm{~h}$. After removal of planktonic cells and three washing steps with saline buffer, the biofilm was stained with a crystal violet solution, followed by dye solubilization with ethanol and measurement of the solution absorbance at $590 \mathrm{~nm}$ as previously described (Ferreira et al. 2007).

\section{Root attachment assays.}

Strains were grown overnight in TY medium, and $10^{8}$ cells were resuspended in nitrogen-free medium (Rolfe et al. 1980). A volume of $1 \mathrm{ml}$ of each bacterial suspension was then placed into a microcentrifuge tube containing a sterile germi- 
nated alfalfa seedling with a root of about $1.5 \mathrm{~cm}$ and was incubated for $8 \mathrm{~h}$ at room temperature. Following that period, the seedling was washed with water three times, and then, attached bacteria were released by vortex in the presence of silica beads. Bacterial suspensions were plated onto TY agar plates, and CFU were counted. Three separate experiments, each containing three technical replicates, were performed for each strain.

\section{Isolation and processing of RNA samples.}

Cells from three biological replicates of the wild-type Sm1021 or the $\Delta e m r R$ mutant grown in GMS medium supplemented with luteolin for $4 \mathrm{~h}$ were harvested, resuspended in RNAprotect bacteria reagent (Qiagen, Hilden, Germany), and total RNA extraction was carried out using the RNeasy mini kit (Qiagen) with DNase treatment, following manufacturer's recommendations. Once absence of residual DNA was confirmed, concentration and purity were determined using a Nanodrop ND-1000 UV-visible spectrophotometer. RNA integrity was checked with an Agilent 2100 Bioanalyser using an RNA Nano assay (Agilent Technologies, Santa Clara, CA, U.S.A.). RNA was processed for use on Affymetrix (Santa Clara, CA, U.S.A.) GeneChip Medicago/Sinorhizobium Genome Arrays as previously described (Santos et al. 2010).

\section{Microarray analysis.}

Scanned arrays were first analyzed using Affymetrix Expression Console software to assure that all quality parameters were in the recommended range. Subsequent analysis was carried out with DNA-Chip Analyzer 2008. First a digital mask was applied, leaving for analysis only the 8,305 probe sets on the array representing $S$. meliloti transcripts. Then the six arrays were normalized to a baseline array with median CEL intensity by applying an invariant set-normalization method (Li and Wong 2001b). Normalized CEL intensities of the arrays were used to obtain model-based gene expression indices based on a perfect match-only model ( $\mathrm{Li}$ and Wong 2001a). Replicate data (triplicates) for each of the S. meliloti wild-type and $\Delta e m r R$ deletion mutant strains were weighted gene-wise by using inverse squared standard error as weights. Genes compared were considered to be differentially expressed if the $90 \%$ lower confidence bound of the fold change between experiment and baseline was above 1.2, resulting in 285 differentially expressed transcripts with a median FDR of $0.9 \%$. The lower confidence bound criterion meant that we can be $90 \%$ confident that the fold change was a value between the lower confidence bound and a variable upper confidence bound. $\mathrm{Li}$ and Wong (2001b) have shown that the lower confidence bound is a conservative estimate of the fold change and, therefore, more reliable as a ranking statistic for changes in gene expression.

\section{Real-time qRT-PCR.}

DNA microarray data were validated by real-time qRT-PCR. For reverse transcription, $1 \mu \mathrm{g}$ of total RNA from $S$. meliloti 1021 and the $\Delta e m r R$ deletion mutant strains, derived from three independent samples, was used. cDNA was synthesized using TaqMan reverse transcription reagents (Applied Biosystems, Foster City, CA, U.S.A.) according to the manufacturer's instructions. Primers used to amplify selected $S$. meliloti genes were designed using Primer Express 3.0 software (Applied Biosystems). RT-PCR amplification mixtures used $400 \mathrm{ng}$ of template cDNA, $2 \times$ SYBR Green PCR Master Mix, and 0.4 $\mathrm{mM}$ of reverse and forward primers for each gene in a total volume of $25 \mu \mathrm{l}$. Reactions containing nuclease-free water instead of the reverse transcriptase were included as negative control. Reactions were performed using a model 7500 Ther- mocycler (Applied Biosystems). The expression ratio of the target genes was determined relative to reference gene hemA, which showed no variation in the transcript abundance under the experimental conditions used. Relative quantification of gene expression by real-time RT-PCR was determined by applying the $\Delta \Delta \mathrm{C}_{\mathrm{t}}$ method (Pfaffl 2001).

\section{Production and recovery of extracellular polysaccharides from bacterial culture supernatants.}

To assess succinoglycan production, the different $S$. meliloti strains were cultivated in $50 \mathrm{ml}$ of GMS medium supplemented with $10 \mu \mathrm{M}$ luteolin for 10 days at $30^{\circ} \mathrm{C}$, with orbital agitation. Bacterial cells were removed by centrifugation $(20,000 \times g$, $15 \mathrm{~min}$ ), and the polysaccharide present in culture supernatants was precipitated with $3 \%$ (wt/vol) $\mathrm{CPC}$, was air dried, and was resuspended in the same volume of $3 \%$ (wt/vol) $\mathrm{NaCl}$. Total sugars were quantified by the HCl-L-Cysteine method (Chaplin and Kennedy 1986).

\section{Siderophore production.}

The presence of siderophores was measured by CAS assay (Schwyn and Neilands 1987) with modifications. Briefly, overnight cultures of $S$. meliloti 1021, the $\Delta e m r R$ deletion mutant, and complemented mutant grown in TY medium were diluted to an initial $\mathrm{OD}_{600 \mathrm{~nm}}=0.1$ in GMS medium supplemented with luteolin $(10 \mu \mathrm{M})$. Strains in these conditions were cultured overnight at $30^{\circ} \mathrm{C}$, were concentrated tenfold, were inoculated $(10 \mu \mathrm{l})$ on the surface of the CAS-GMS agar plates, and were incubated at $30^{\circ} \mathrm{C}$ for 3 days. Modified CAS-GMS agar plates were prepared as follows: $60.5 \mathrm{mg}$ CAS was dissolved in 50 $\mathrm{ml}$ of deionized water and was mixed with $10 \mathrm{ml}$ of iron (III) solution $\left(1 \mathrm{mM} \mathrm{FeCl}{ }_{3} \cdot 6 \mathrm{H}_{2} \mathrm{O}, 10 \mathrm{mM} \mathrm{HCl}\right)$. With stirring, this solution was slowly mixed with $72.9 \mathrm{mg}$ of hexadecyltrimethylammonium dissolved in $40 \mathrm{ml}$ of water. The resultant dark-blue solution was sterilized and mixed with $900 \mathrm{ml}$ of GMS agar before plating.

\section{Heat and osmotic stresses.}

For heat shock, cells were grown in GMS supplemented with $10 \mu \mathrm{M}$ luteolin for $4 \mathrm{~h}$ and were then submitted to a static incubation at 30 and at $42^{\circ} \mathrm{C}$ in a water bath for $30 \mathrm{~min}$. At minutes 15 and 30, an aliquot of $100 \mu \mathrm{l}$ was serially diluted and plated onto TY agar. After $72 \mathrm{~h}$ of incubation at $30^{\circ} \mathrm{C}$, CFU were counted. For osmotic stress, cells were grown in GMS supplemented with $10 \mu \mathrm{M}$ luteolin for $18 \mathrm{~h}$, followed by the addition of $0.3 \mathrm{M} \mathrm{NaCl}$. $\mathrm{OD}_{600 \mathrm{~nm}}$ was measured until cultures reached $65 \mathrm{~h}$ of growth.

\section{Zone inhibition assays.}

Bacterial cultures were grown overnight and approximately $10^{6}$ cells were plated in TY agar. Sterile paper disks $6 \mathrm{~mm}$ in diameter were placed on the surface of the agar. A total of 10 $\mu 1$ of $p$-coumaric acid $(1.5 \mathrm{mg} / \mathrm{ml}$ dissolved in $95 \%$ ethanol), berberine $(3 \mathrm{mg} / \mathrm{ml})$, genistein $(3 \mathrm{mg} / \mathrm{ml}$ dissolved in DMSO), SDS $\left(10 \%\right.$ [wt/vol]), $1 \mathrm{M} \mathrm{H}_{2} \mathrm{O}_{2}$, cumene hydroperoxide (5\% [wt/vol]), DOC (10\% [wt/vol]), novobiocin $(20 \mathrm{mg} / \mathrm{ml})$, malachite green $(5 \%[\mathrm{wt} / \mathrm{vol}])$, or crystal violet $(1 \%[\mathrm{wt} / \mathrm{vol}])$ was pipetted onto separate disks. The plates were incubated for $72 \mathrm{~h}$, and the diameters of the zones of inhibition were measured (in millimeters).

\section{Statistical analysis.}

All quantitative data was obtained from at least three independent assays. Standard deviation was used to calculate error bars. The $t$-tests to determine $P$ values were performed using GraphPad Prism 5.0 software. Differences were considered to be statistically significant if the $P$ value was lower than 0.05 . 


\section{ACKNOWLEDGMENTS}

This work was supported by FEDER and Fundação para a Ciência e a Tecnologia, Portugal (contracts PTDC/BIA-MIC/113733/2009 and PEstOE/EQB/LA0023/2011) and a doctoral grant to M. R. Santos.

\section{LITERATURE CITED}

Abola, A. P., Willits, M. G., Wang, R. C., and Long, S. R. 1999. Reduction of adenosine-5'-phosphosulfate instead of 3'-phosphoadenosine-5' phosphosulfate in cysteine biosynthesis by Rhizobium meliloti and other members of the family Rhizobiaceae. J. Bacteriol. 181:5280-5287.

Altschul, S. F., Madden, T. L., Schaffer, A. A., Zhang, J., Zhang, Z., Miller, W., and Lipman, D. J. 1997. Gapped BLAST and PSI-BLAST: A new generation of protein database search programs. Nucleic Acids Res. 25:3389-3402.

Barnett, M. J., Toman, C. J., Fisher, R. F., and Long, S. R. 2004. A dualgenome symbiosis chip for coordinate study of signal exchange and development in a prokaryote-host interaction. Proc. Natl. Acad. Sci. U. S. A. 101:16636-16641.

Barnett, M. J., Bittner, A. N., Toman, C. J., Oke, V., and Long, S. R. 2012. Dual RpoH sigma factors and transcriptional plasticity in a symbiotic bacterium. J. Bacteriol. 194:4983-4994.

Beck, S., Marlow, V. L., Woodall, K., Doerrler, W. T., James, E. K., and Ferguson, G. P. 2008. The Sinorhizobium meliloti MsbA2 protein is essential for the legume symbiosis. Microbiology. 154:1258-1270.

Bélanger, L., and Charles, T. C. 2013. Members of the Sinorhizobium meliloti ChvI regulon identified by a DNA binding screen. BMC Microbiol. 13:132.

Bélanger, L., Dimmick, K. A., Fleming, J. S., and Charles, T. C. 2009. Null mutations in Sinorhizobium meliloti exoS and chvI demonstrate the importance of this two-component regulatory system for symbiosis. Mol. Microbiol. 74:1223-1237.

Beringer, J. E. 1974. R factor transfer in Rhizobium leguminosarum. J. Gen. Microbiol. 84:188-198.

Burse, A., Weingart, H., and Ullrich, M. S. 2004. The phytoalexin-inducible multidrug efflux pump AcrAB contributes to virulence in the fire blight pathogen, Erwinia amylovora. Mol. Plant-Microbe Interact. 17:43-54.

Campbell, G. R. O., Sharypova, L. A., Scheidle, H., Jones, K. M., Niehaus, K., Becker, A., and Walker, G. C. 2003. Striking complexity of lipopolysaccharide defects in a collection of Sinorhizobium meliloti mutants. J. Bacteriol. 185:3853-3862.

Capela, D., Carrere, S., and Batut, J. 2005. Transcriptome-based identification of the Sinorhizobium meliloti NodD1 regulon. Appl. Environ. Microbiol. 71:4910-4913.

Chaplin, M. F., and Kennedy, S. F. 1986. Carbohydrate Analysis: A Practical Approach. IRL Press, Washington, DC.

Chen, E. J., Fisher, R. F., Perovich, V. M., Sabio, E. A., and Long, S. R. 2009. Identification of direct transcriptional target genes of ExoS/ChvI two-component signaling in Sinorhizobium meliloti. J. Bacteriol. 191:6833-6842.

Cheng, H. P., and Walker, G. C. 1998. Succinoglycan production by Rhizobium meliloti is regulated through the ExoS-ChvI two-component regulatory system. J. Bacteriol. 180:20-26.

Cosme, A. M., Becker, A., Santos, M. R., Sharypova, L. A., Santos, P. M., and Moreira, L. M. 2008. The outer membrane protein TolC from Sinorhizobium meliloti affects protein secretion, polysaccharide biosynthesis, antimicrobial resistance, and symbiosis. Mol. Plant-Microbe Interact. 21:947-957.

Cronan, G. E., and Keating, D. H. 2004. Sinorhizobium meliloti sulfotransferase that modifies lipopolysaccharide. J. Bacteriol. 186:4168-4176.

Cuthbertson, L., and Nodwell, J. R. 2013. The TetR family of regulators. Microbiol. Mol. Biol. Rev. 77:440-475.

Eda, S., Mitsui, H., and Minamisawa, K. 2011. Involvement of the SmeAB multidrug efflux pump in resistance to plant antimicrobials and contribution to nodulation competitiveness in Sinorhizobium meliloti. Appl. Environ. Microbiol. 77:2855-2862.

Eumkeb, G., Siriwong, S., and Thumanu, K. 2012. Synergistic activity of luteolin and amoxicillin combination against amoxicillin-resistant Escherichia coli and mode of action. J. Photochem. Photobiol. B. 117:247-253.

Ferreira, A. S., Leitão, J. H., Sousa, S. A., Cosme, A. M., Sá-Correia, I., and Moreira, L. M. 2007. Functional analysis of Burkholderia cepacia genes $b c e D$ and $b c e F$, encoding a phosphotyrosine phosphatase and a tyrosine autokinase, respectively: Role in exopolysaccharide biosynthesis and biofilm formation. Appl. Environ. Microbiol. 73:524-534.

Fields, A. T., Navarrete, C. S., Zare, A. Z., Huang, Z., Mostafavi, M., Lewis, J. C., Rezaeihaghighi, Y., Brezler, B. J., Ray, S., Rizzacasa, A.
L., Barnett, M. J., Long, S. R., Chen, E. J., and Chen, J. C. 2012. The conserved polarity factor PodJ1 impacts multiple cell envelope-associated functions in Sinorhizobium meliloti. Mol. Microbiol. 84:892-920.

Finan, T. M., Hartweig, E., LeMieux, K., Bergman, K., Walker, G. C., and Signer, E. R. 1984. General transduction in Rhizobium meliloti. J. Bacteriol. 159:120-124.

Gibson, K. E., Campbell, G. R., Lloret, J., and Walker, G. C. 2006. CbrA is a stationary-phase regulator of cell surface physiology and legume symbiosis in Sinorhizobium meliloti. J. Bacteriol. 188:4508-4521.

González-Pasayo, R., and Martínez-Romero, E. 2000. Multiresistance genes of Rhizobium etli CFN42. Mol. Plant-Microbe Interact. 13:572577.

Hanahan, D. 1983. Studies on transformation of Escherichia coli with plasmids. J. Mol. Biol. 166:557-580.

Hellweg, C., Puhler, A., and Weidner, S. 2009. The time course of the transcriptomic response of Sinorhizobium meliloti 1021 following a shift to acidic pH. BMC Microbiol. 9:37.

Katzen, F., Becker, A., Ielmini, M. V., Oddo, C. G., and Ielpi, L. 1999. New mobilizable vectors suitable for gene replacement in gram-negative bacteria and their use in mapping of the $3^{\prime}$ end of the Xanthomonas campestris pv. campestris gum Operon. Appl. Environ. Microbiol. 65:278-282.

Keller, M., Roxlau, A., Weng, W. M., Schmidt, M., Quandt, J., Niehaus, K., Jording, D., Arnold, W., and Puhler, A. 1995. Molecular analysis of the Rhizobium meliloti mucR gene regulating the biosynthesis of the exopolysaccharides succinoglycan and galactoglucan. Mol Plant-Microbe Interact. 8:267-277.

Krummenacher, P., and Narberhaus, F. 2000. Two genes encoding a putative multidrug efflux pump of the RND/MFP family are cotranscribed with an rpoH gene in Bradyrhizobium japonicum. Gene. 241:247-254.

Leigh, J. A., and Lee, C. C. 1988. Characterization of polysaccharides of Rhizobium meliloti exo mutants that form ineffective nodules. J. Bacteriol. 170:3327-3332.

Lennox, E. S. 1955. Transduction of linked genetic characters of the host by bacteriophage P1. Virology. 1:190.

Li, C., and Wong, W. H. 2001a. Model-based analysis of oligonucleotide arrays: Expression index computation and outlier detection. Proc. Natl. Acad. Sci. U. S. A. 98:31-36.

Li, C., and Wong, W. H. 2001b. Model-based analysis of oligonucleotide arrays: Model validation, design issues and standard error application. Genome Biol. 2:RESEARCH0032.

Lindemann, A., Koch, M., Pessi, G., Müller, A. J., Balsiger, S., Hennecke, H., and Fischer, H.-M. 2010. Host-specific symbiotic requirement of BdeAB, a RegR-controlled RND-type efflux system in Bradyrhizobium japonicum. FEMS (Fed. Eur. Microbiol. Soc.) Microbiol. Lett. 312:184191.

Lomovskaya, O., Lewis, K., and Matin, A. 1995. EmrR is a negative regulator of the Escherichia coli multidrug resistance pump EmrAB. J. Bacteriol. 177:2328-2334.

López-Lara, I. M., Gao, J.-L., Soto, M. J., Solares-Pérez, A., Weissenmayer, B., Sohlenkamp, C., Verroios, G. P., Thomas-Oates, J., and Geiger, O. 2005. Phosphorus-free membrane lipids of Sinorhizobium meliloti are not required for the symbiosis with alfalfa but contribute to increased cell yields under phosphorus-limiting conditions of growth. Mol. PlantMicrobe Interact. 18:973-982.

de Lucena, D. K. C., Pühler, A., and Weidner, S. 2010. The role of sigma factor RpoH1 in the pH stress response of Sinorhizobium meliloti. BMC Microbiol. 10:265.

Lynch, D., O'Brien, J., Welch, T., Clarke, P., Cuív, P. O., Crosa, J. H., and O'Connell, M. 2001. Genetic organization of the region encoding regulation, biosynthesis, and transport of rhizobactin 1021, a siderophore produced by Sinorhizobium meliloti. J. Bacteriol. 183:2576-2585.

Ma, D., Alberti, M., Lynch, C., Nikaido, H., and Hearst, J. E. 1996. The local repressor AcrR plays a modulating role in the regulation of acrAB genes of Escherichia coli by global stress signals. Mol. Microbiol. 19:101-112.

Meade, H. M., Long, S. R., Ruvkun, G. B., Brown, S. E., and Ausubel, F. M. 1982. Physical and genetic characterization of symbiotic and auxotrophic mutants of Rhizobium meliloti induced by transposon Tn5 mutagenesis. J. Bacteriol. 149:114-122.

Moreira, L. M., Becker, J. D., Puhler, A., and Becker, A. 2000. The Sinorhizobium meliloti ExpE1 protein secreted by a type I secretion system involving ExpD1 and ExpD2 is required for biosynthesis or secretion of the exopolysaccharide galactoglucan. Microbiology. 146:2237-2248.

Morris, J., and González, J. E. 2009. The novel genes emmABC are associated with exopolysaccharide production, motility, stress adaptation, and symbiosis in Sinorhizobium meliloti. J. Bacteriol. 191:5890-5900.

Neidhardt, F. C., Bloch, P. L., and Smith, D. F. 1974. Culture medium for enterobacteria. J. Bacteriol. 119:736-747.

Okusu, H., Ma, D., and Nikaido, H. 1996. AcrAB efflux pump plays a 
major role in the antibiotic resistance phenotype of Escherichia coli multiple-antibiotic-resistance (Mar) mutants. J. Bacteriol. 178:306-308.

Palumbo, J. D., Kado, C. I., and Phillips, D. A. 1998. An isoflavonoidinducible efflux pump in Agrobacterium tumefaciens is involved in competitive colonization of roots. J. Bacteriol. 180:3107-3113.

Pfaffl, M. W. 2001. A new mathematical model for relative quantification in real-time RT-PCR. Nucleic Acids Res. 29:e45.

Ramos, J. L., Martínez-Bueno, M., Molina-Henares, A. J., Terán, W., Watanabe, K., Zhang, X., Gallegos, M. T., Brennan, R., and Tobes, R. 2005. The TetR family of transcriptional repressors. Microbiol. Mol. Biol. Rev. 69:326-356.

Reuber, T. L., and Walker, G. C. 1993. Biosynthesis of succinoglycan, a symbiotically important exopolysaccharide of Rhizobium meliloti. Cell. 74:269-280.

Reuber, T. L., Urzainqui, A., Glazebrook, J., Reed, J. W., and Walker, G. C. 1991. Rhizobium meliloti exopolysaccharides. Structures, genetic analyses, and symbiotic roles. Ann. N. Y. Acad. Sci. 646:61-68.

Reyes, F., Roldan, M. D., Klipp, W., Castillo, F., and Moreno-Vivian, C. 1996. Isolation of periplasmic nitrate reductase genes from Rhodobacter sphaeroides DSM 158: Structural and functional differences among prokaryotic nitrate reductases. Mol. Microbiol. 19:1307-1318.

Rolfe, B. G., Gresshoff, P. M., Shine, J., and Vincent, J. M. 1980. Interaction between a non-nodulating and an ineffective mutant of Rhizobium trifolli resulting in effective (nitrogen-fixing) nodulation. Appl. Environ. Microbiol. 39:449-452.

Sambrook, J., and Russell, D.W. 2001. Molecular Cloning: A Laboratoty Manual. Cold Spring Harbor Laboratory Press, Cold Spring Harbor, NY, U.S.A.

Santos, M. R., Cosme, A. M., Becker, J. D., Medeiros, J. M., Mata, M. F., and Moreira, L. M. 2010. Absence of functional TolC protein causes increased stress response gene expression in Sinorhizobium meliloti. BMC Microbiol. 10:180.
Schwyn, B., and Neilands, J. B. 1987. Universal chemical assay for the detection and determination of siderophores. Anal. Biochem. 160:4756.

Simon, R., Priefer, U., and Puhler, A. 1983. A broad-host-range mobilization system for in vivo genetic engineering: Transposon mutagenesis in gram-negative bacteria. Biotechnology. 1:784-791.

Soto, M. J., Fernandez-Pascual, M., Sanjuan, J., and Olivares, J. 2002. A fadD mutant of Sinorhizobium meliloti shows multicellular swarming migration and is impaired in nodulation efficiency on alfalfa roots. Mol. Microbiol. 43:371-382.

Thompson, J. D., Higgins, D. G., and Gibson, T. J. 1994. CLUSTAL W: Improving the sensitivity of progressive multiple sequence alignment through sequence weighting, position-specific gap penalties and weight matrix choice. Nucleic Acids Res. 22:4673-4680.

Vincent, J. M. 1970. Manual for the practical study of root nodule bacteria. IBP Handbook. No. 15. Oxford: Blackwell Scientific Publications.

Wang, C., Kemp, J., Da Fonseca, I. O., Equi, R. C., Sheng, X., Charles, T. C., and Sobral, B. W. S. 2010. Sinorhizobium meliloti 1021 loss-offunction deletion mutation in $c h v I$ and its phenotypic characteristics. Mol. Plant-Microbe Interact. 23:153-160.

Wells, D. H., Chen, E. J., Fisher, R. F., and Long, S. R. 2007. ExoR is genetically coupled to the ExoS-ChvI two-component system and located in the periplasm of Sinorhizobium meliloti. Mol. Microbiol. 64:647-664.

Wenzel, M., Lang, K., Günther, T., Bhandari, A., Weiss, A., Lulchev, P., Szentgyörgyi, E., Kranzusch, B., and Göttfert, M. 2012. Characterization of the flavonoid-responsive regulator FrrA and its binding sites. J. Bacteriol. 194:2363-2370.

York, G. M., and Walker, G. C. 1997. The Rhizobium meliloti exoK gene and prsD/prsE/exs $H$ genes are components of independent degradative pathways which contribute to production of low-molecular-weight succinoglycan. Mol. Microbiol. 25:117-134 